Bond University

Research Repository

\title{
Psychological Impacts of Remote Working Under Social Distancing Restrictions
}

\author{
Baumann, Oliver; Sander, Elizabeth J
}

Published in:

Handbook of Research on Remote Work and Worker Well-Being in the Post-COVID-19 Era

DOI:

10.4018/978-1-7998-6754-8.ch001

Licence:

Other

Link to output in Bond University research repository.

Recommended citation(APA):

Baumann, O., \& Sander, E. J. (2021). Psychological Impacts of Remote Working Under Social Distancing Restrictions. In D. Wheatley, I. Hardill , \& S. Buglass (Eds.), Handbook of Research on Remote Work and Worker Well-Being in the Post-COVID-19 Era (pp. 1-17). IGI Global. https://doi.org/10.4018/978-1-7998-67548.ch001

\section{General rights}

Copyright and moral rights for the publications made accessible in the public portal are retained by the authors and/or other copyright owners and it is a condition of accessing publications that users recognise and abide by the legal requirements associated with these rights.

For more information, or if you believe that this document breaches copyright, please contact the Bond University research repository coordinator. 


\title{
Chapter 1 \\ Psychological Impacts of Remote Working Under Social Distancing Restrictions
}

\author{
Oliver Baumann \\ Bond University, Australia \\ Elizabeth (Libby) J. Sander \\ Bond University, Australia
}

\begin{abstract}
The coronavirus (COVID-19) pandemic has resulted in a swift and dramatic global shift in the location of work for many employees. Organizations around the world have implemented remote work arrangements to allow continuity of service while conforming with social distancing requirements. As a result of ongoing uncertainty regarding the current and future pandemics, reduced costs associated with housing employees remotely, and survey results suggesting employees are reluctant to return to a primarily office-based work model, many organisations are implementing ongoing remote arrangements for their employees. This chapter provides a review of current research on the psychological effects of remote working. Recommendations are made regarding future research directions across various remote work environments that will enhance understanding of the psychological effects of remote work under social distancing.
\end{abstract}

\section{INTRODUCTION}

The coronavirus (COVID-19) pandemic has forced a swift and dramatic shift in the way we work (Carnevale \& Hatak, 2020) as organizations around the world have implemented working from home arrangements to allow continuity of service, while conforming with social distancing requirements. Remote work, which has previously been available to a limited group of employees (Allen et al., 2015), or as the privilege of the self-employed, has therefore become the new norm for many. Moreover, the uncertainty regarding the duration and impact of the pandemic (Altig et al. 2020) means that many organizations 
are considering longer-term working from home arrangements. Finally, greater availability of technology to support remote working, combined with substantial reductions in direct costs for organizations (Manocheri \& Pinkerton, 2003) suggest that work-from-home (or blended working) is likely to become much more common.

Work environments present both benefits and risks for mental health, and traditional work arrangements have been the centre of extensive investigations over the last century (Bliese et al., 2017; Cooper, 1976; Stansfeld \& Candy, 2006; Thayer et al., 2010;). There is much less data, however, on the psychological impacts of remote work arrangements. A recent meta-analysis of the literature on home offices and telecommuters has identified a range of topics and issues that are at the centre of current research (de Macêdo, et al. 2020). Broadly, the dominant themes in the reviewed literature highlighted advantages of increased productivity, increased employee flexibility and reduced stress, and potential disadvantages of increased isolation, intensified work, and family-work conflicts. More research, however, is necessary, to provide a comprehensive understanding of the impacts of work-from-arrangements across a broad range of industries and employee demographics.

As a result of COVID-19, the number of employees working from home has increased dramatically around the world. For instance, in May 2020, 35\% of the US workforce worked entirely from home, compared to just $8 \%$ in February 2020 (Bick et al., 2020). Even industries that traditionally do not rely much on work-from-home arrangements were forced to introduce them (Banerjee et al., 2020). The COVID-19 scenario presents a unique opportunity to evaluate the positive and negative psychological impacts of working from home on a large scale. Better knowledge about the psychological impacts of working from home will allow for informed decision-making and proactive interventions to ensure that work arrangements enhance well-being and performance, rather than impeding them. As mentioned above, there are several key outcome variables at the focus of research on work at-home-environments. However, rather than exploring those outcome measures in a bottom-up fashion, in this chapter we focus on the mediating inner mechanisms, namely motivation and the fulfilment of basic psychological needs, to provide structure for future research. We begin by presenting a model of how work arrangements might act via motivation and need satisfaction to influence performance and well-being utilising self-determination theory (Ryan \& Deci, 2017). Subsequently, we assess the literature on remote work arrangements within this framework and outline suggestions for future research on the psychological impacts of remote work under social distancing restrictions.

\section{Work Arrangements and Motivation}

For an organization to be successful and profitable, it is crucial that it supports employees to achieve and maintain a high level of performance and well-being. Individual well-being has been shown to be an important precursor to both individual and organization performance (Ford, Cerasoli, Higgins \& Decesare, 2011; Taris \& Schreurs, 2009). Fundamentally, work performance is underpinned by motivation (Deci et al., 2017). Importantly, there are two types ${ }^{1}$ of motivation, extrinsic motivation which is reliant on external rewards and pressures (such as pay and deadlines), and intrinsic motivation that derives both from within the individual and the task itself (i.e. fuelled by interest; Deci, 1971). While extrinsic motivation can lead to elevated performance, especially for tasks that are easily quantifiable and for which quality is less relevant, intrinsic motivation is useful for tasks in which qualitative excellence and creativity matters (Covington \& Mueller, 2001). Extrinsic motives not only shift attention away from the task to the reward (Pittman et al., 1983), but may make behaviour dependent on external-regulation 
and inhibit independent thought (Ryan, 1993). More recent work has highlighted that the negative effect of external rewards on intrinsically rewarding tasks may be explained by a distractor effect, which may eventually wear off in real-life settings (Reiss, 2012). In any case, given that monetary remuneration is an integral part of employment, employers are less focussed on avoiding extrinsic motivators, and seek instead to enhance intrinsic motivators. In one study Kuvaas and colleagues (2017) surveyed thousands of employees in retail, finance, and technology organizations in Norway and found that intrinsic motivation (derived from their role and associated activities) was uniformly associated with positive employee outcomes such as performance and well-being, while extrinsic motivation (monetary rewards) was found to be negatively related, or unrelated to these outcomes. So, if intrinsic motivation is so important for work performance and well-being, how can we foster it? In the next section we propose a model of how work from home arrangements might act via motivation and need satisfaction to influence performance and well-being utilising self-determination theory (Ryan \& Deci, 2017).

\section{Self-determination Theory and Remote Work}

According to Ryan's and Deci's self-determination theory (Ryan \& Deci, 2017) intrinsic motivation is underpinned and promoted by three basic and universal psychological needs: competence, autonomy, and relatedness. These three needs are also referred to as organismic psychological needs, borrowing the name from the term organism, a living being that reacts to and is dependent on its environment. Ryan and Deci (2017) posit that in addition to biological needs, in order to thrive and grow, humans need to satisfy certain psychological requirements. According to self-determination theory, only activities and environments that fulfill these three basic needs will support individuals in developing the intrinsic motivation that is crucial for productivity and well-being (see Figure 1). Failing to satisfy those basic psychological needs is likely to lead not only to a lack of motivation, but ultimately poorer mental and physical health outcomes. In the following sections we will define these basic needs, and discuss how they can be conceptualised and explored as potential mediators of both positive and negative outcomes of work-from-home arrangements.

\section{Competence}

Competence refers to the psychological need of individuals to be successful in interactions with one's environment (White, 1959). Competence also reflects the drive to challenge and extend capabilities, and to seek out opportunities for personal growth (Steers \& Spencer, 1977). To develop a sense of competence and a growth mindset it is important that the task provides an optimal level of challenge, i.e. avoiding boredom and frustration by matching the requirements of the task with the capabilities of the employee (Nakamura \& Csikszentmihalyi, 2002). Further, and equally important, is the provision of timely and informative feedback, since obtaining feedback is vital for employees to develop a sense of competence (Butler \& Nissan, 1986). Information about task performance opportunities for further development do not necessarily have to be provided by supervisors or co-workers but could also be intrinsic to the task (Anderson et al., 2001). Work-from-home arrangements typically lack many of the spontaneous opportunities for feedback that occur in classical office environments, such as during incidental conversations with co-workers and supervisors in the lift or at lunch breaks. 
Figure 1. The self-determination model of motivation by Ryan \& Deci (2017) applied to the workplace

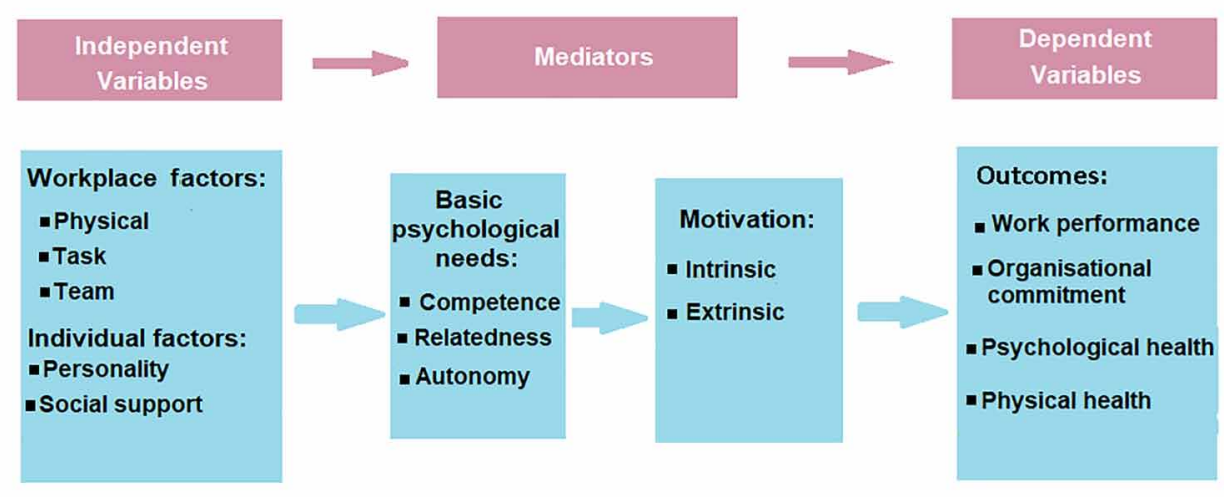

The effects of reduced opportunities for feedback became apparent in a study by Bloom and colleagues (2015). They conducted the first large scale long-term experimental study on the psychological effects of work-from-home arrangements, by sampling 16,000 call centre employees who were randomly assigned to work from home or in the office for 9 months. Bloom and colleagues (2015) found that overall the effect of working from home was positive, quantitative performance went up by $13 \%$ (mainly due to shorter break times and less sick leave) and qualitative performance stayed the same. Importantly, however, and relevant to the need for competence, the rate of promotions (to advanced functions or team leadership) was $50 \%$ lower in the work-from-home group. Follow-up interviews and focus-groups conducted by Bloom and colleagues (2015) further revealed that supervisors were less likely to notice good performance of work-at-home employees and were therefore also less likely to promote them, i.e. "out of sight, out of mind." Intriguingly, the increased productivity by the work-from-home group could potentially be partially explained by the lack of recognition, since the reduced visibility of achievements might lead to heightened desire by employees to appear productive, however, this effect may be extinguished over time if not successful. The negative effect of work-from-home arrangements on career development is likely to be even further compounded over time, with work-from-home employees losing out on developing interpersonal skills and relationships that are crucial for advancing to managerial positions (Mencl et al., 2016). Particularly for individuals with strong competence motivation, the reduced opportunity to receive performance feedback and recognition face-to-face may lead to reduced overall intrinsic motivation (Matsui et al., 1982), and subsequent lower levels of performance and well-being (Ryan \& Deci, 2017). While doing overtime in the office might be a meaningful voluntary form of investment with the aim of achieving higher wages or promotions in the long run, extra hours at home do not seem to offer the same returns and have the additional potential to cause work-family conflicts (Song, 2009). It is therefore essential that work-at-home arrangements consider means to ensure that employees receive appropriate feedback on their performance. A current trend in delivering real-time performance feedback is to embed gamification elements to human-computer interfaces. This can be done by awarding automated achievements, such as batches, when employees meet pre-specified performance goals (Anderson et al., 2013, Grant \& Betts, 2013). Gamification has generally been found to provide positive impacts on performance in a range of industries (Hamari, et al. 2014), and even increase the perceived meaningfulness of the task (Sailer et al. 2017). The evidence base, however, is still relatively limited, and long-term effects in particular will require further investigation. Furthermore, automated, real-time feedback is 
not an option for situations when objective indices of performance are not available, or on long-term projects where goals, metrics and personnel are likely to change with relative frequency. Furthermore, research has shown that employees may develop negative attitudes to gamification, since the inherent focus on extrinsic rewards may encourage competitive rather than cooperative behaviours (Hamari et al., 2014). Given the interindividual differences in motivation, it seems likely that gamification will be better suited to competence orientated individuals, than for individuals high in need of relatedness. In addition, individuals that have a high need for competence may become demotivated if the difficulty of the gamified challenges is perceived as too low or too high, therefore leading to boredom or anxiety (Csikzentmihalyi et al., 1993).

One strategy to support individuals who have a high need for relatedness, is to increase the frequency of short formal meetings, in both individual and group settings in order to compensate for the reduced opportunities for informal interactions in work-from home arrangements (Kello, 2015). However, more industry and task specific research will be necessary to develop evidence-based approaches to effectively manage performance for work-from-home arrangements.

\section{Relatedness}

Relatedness is the psychological need to connect emotionally with other people in reciprocal and meaningful relationships (Baumeister \& Leary, 1995, Ryan \& Powelson, 1991). This is a key benefit of the social environment that working with others can provide, and as such is essential for optimising work outcomes for both employees and organizations (Allen et al., 2015). Social psychology research has shown that sociable relationships can emerge seemingly spontaneously among groups of people, if individuals are given both sufficient proximity, and adequate time to build them (Wilder \& Thomson, 1980). Importantly though, not all social interactions are able to satisfy relatedness needs. A key condition for developing satisfying relationships is perceived partner responsiveness (Reis, 2014). Work-from-home environments are clearly distinct to office environments in regard to the opportunities they provide to build and engage in responsive social interactions, since they offer reduced opportunities to engage socially with co-workers. In the aforementioned study by Bloom and colleagues (2015) the experimental work-from-home group was offered the choice to permanently switch to this arrangement, however half of the workers refused the offer, citing the lack of social contacts as a key reason. This finding dovetails with a study by Ozcelik and Barsade (2011), which investigated the links between perceived loneliness (i.e. the deprivation of close relationships) and work performance. The study measured loneliness in employees by using self-reports (i.e. UCLA Loneliness scale, Russel, 1996) as well as observations of co-workers and supervisors. The researchers assessed a range of demographic (e.g., education level, age, and organizational tenure) and psychological variables (e.g., extraversion, positive and negative affectivity) in their analysis, finding that loneliness was a significant negative predictor for task performance, team role performance, and affective commitment (Ozcelik \& Barsade, 2011). Further, the effect of loneliness on performance was facilitated by lowered affective commitment to the organization. In other words, the findings indicate that work loneliness leads to emotional withdrawal, which ultimately leads to deteriorating performance and well-being (Ozcelik \& Barsade, 2011). Importantly, a recent meta-analysis (Holt-Lunstad et al., 2015) highlighted that the negative effects of loneliness are not only psycho-behavioural, but that loneliness can have negative health implications. More specifically, this analysis indicated the effects of loneliness on mortality is comparable to smoking 15 cigarettes a day and that, somewhat surprisingly, loneliness is more predictive of premature death in those under 65 than in 
older age groups (Holt-Lunstad et al., 2015). Given concerns over the effects of the pandemic restrictions on the career development of younger employees, including developing networks and receiving social support, these findings are particularly significant.

Achor and colleagues (2018) followed up on these findings by investigating the demographic and professional profile that is most strongly associated with loneliness in a longitudinal survey of US fulltime workers. Firstly, they found that several basic demographic factors such as age, gender, ethnicity, and even salary or job security, did not have much bearing on the severity of loneliness. In contrast, the nature of work had a robust effect, showing that professions that require less frequent social contact due to conducting more work on an individual basis (e.g., legal work, science and engineering) were more prone to high levels of loneliness than occupations that demand a high degree of social interaction (e.g. social work, marketing and sales). The most significant predictors of loneliness, however, were demographic factors related to an individual's private social life. Specifically, the smaller the private social support network, e.g., due to childlessness or the absence of a life partner or close friendships, the more prone to loneliness workers were at work. The results by Achor and colleagues (2018) further highlighted that, while any type of social support provided by an organization significantly improved well-being and performance, the most effective predictor on all human resource metrics was the presence of shared meaning across co-workers. The notion that shared meaning, or shared mental-models relating to how to carry out work, or the objectives of the organization for example, are crucial predictors or team processes and performance are not new (e.g. Mathieu et al., 2000). However, this newly discovered relationship with loneliness further highlights how important it is to provide employees with opportunities to fulfill their need for relatedness. The question remains though as to how to achieve this in work-from-home arrangements?

Video conferencing technologies provide a convenient and cost-effective means to facilitate remote work-related communication, but its use is limited for social interactions. As highlighted by Sander and Baumann (2020), teleconferencing has its side-effects and can reduce psychological well-being. Key factors are that teleconferences omit and supress nonverbal social cues (i.e., subtle aspects of body-language) that people typically use to communicate their feelings (Mehrabian, 1972). Moreover, research has shown that also the heightened focus on facial cues and the ability to see oneself can act as a stressor (Vergallito, et al., 2020). Previous research has also shown that virtual teams tend to express less excitement, social support, and trust than real-world teams (Rice and Love, 1987), however building efficient and supportive virtual teams is possible (Jarvenpaa \& Leidner, 1999). Hawisher and Moran (1993) pointed out that virtual teams require an "intense need for response', so that failing to acknowledge an individual's initiatives and actions can quickly lead to erosion of trust, and rapid disintegration of the cohesion of the virtual group. As such, the use of traditional videoconferencing tools might not be optimal to create social bonds and shared mental models among co-workers. One avenue to overcome these limitations may be the use of novel immersive virtual reality (VR) technology for team meetings. Recent research has indicated that compared to traditional video-conferencing methods, VR-based environments increase not only the sense of presence, but also of team membership (Oprean et al., 2017). This may be because the increased presence might be mediated by increased immersion afforded by the wider fields of view offered by VR technology compared to traditional computer displays. Research in this area is, however, still in its relative infancy, and larger more comprehensive studies will be necessary to fully evaluate the potential of VR technology in generating socially cohesive co-worker experiences. 
Psychological Impacts of Remote Working Under Social Distancing Restrictions

\section{Autonomy}

Autonomy is the psychological need to voluntarily initiate, control, and regulate behaviour (Ryan \& Deci, 2017). In other words, the need for autonomy relates to the innate drive to make decisions and behave in ways that are congruent with our personal preferences. In the study by Bloom and colleagues (2015), productivity in the randomly selected work-from-home group increased by $13 \%$ relative to the office control-group. More impressively yet, in the second part of the study, in which employees were permitted to choose whether they wanted to work from home or in the office, the positive productivity difference grew to $22 \%$. This further dramatic increase in productivity can be attributed to a selfselection effect, which shows that increases in productivity are not a uniform effect, but that employees who choose to work from home also contribute the largest increases in productivity. Importantly this study also showed that, in addition to increases in productivity, employees in the work-at-home group also reported subjectively higher satisfaction with work, which was objectively expressed in a 50\% lower turnover rate. This clearly highlights the importance of satisfying employees' autonomy needs as a contributor to enhancing productivity and well-being.

\section{Work Life Balance, Family Issues, and Harassment}

Directly related to the issue of autonomy, and arguably one of the most significant benefits of work-at-home arrangements, is the increased degree of flexibility that it offers (Sanchez et al., 2007). With the percentage of full-time working parents steadily increasing (Australian Bureau of Statistics, 2017; Cantillon et al., 2017; Pew Research Center, 2015), flexibility of work hours and the location of work for employees has been identified as the most important factor to balance work-family demands (Advancing Parental Leave Equality Network, 2019; Troup \& Rose, 2012). Dockery \& Bawa (2014) analysed survey data from 14,000 individuals and confirmed a positive association between working from home and employees' satisfaction with the flexibility to balance work and non-work commitments. Importantly, this effect is positively moderated by the total number of hours worked from home, showing that the more experience employees have with working from home the more they tend to like it. These findings are supported by research by Song \& Goa (2018), which showed that subjective well-being also increased, due to greater control over work schedules and overall better work-life balance (e.g., due to reduced commute times). Moreover, Troup and Rose (2012) found that the positive effects of flexible arrangements are amplified for working women. This is in line with earlier findings, which highlight that flexible work hours are generally related to higher organizational commitment and job satisfaction in workers with family responsibilities (Scandura \& Lankau, 1997). Importantly though, work-at-home arrangements appear to not actually increase the amount of time that employees spend on family activities, but the increased flexibility means that they are better able to manage the dual obligations (Ransome, 2007). A potential downside from this increased flexibility is the blurring of work-life boundaries, leading to family-conflicts and working longer hours (Duxbury \& Higgins, 2001). This potential for work-family conflict seems to be particularly high in the case of involuntary work-from home arrangements, which do not satisfy the employees need for autonomy (e.g. due to an organization's need to reduce cost associated with office space; Lapierre and colleagues, 2016). In the context of the COVID-19 pandemic there have also been several published reports that suggest increases in domestic violence (Das et al., 2020; Jetelina et al., 2020 Peterman et al., 2020). These studies, however, also highlight that the pandemic is a multifactorial issue which involves economic uncertainty, loss of income, food insecurity, curtailing of personal rights 
and freedom of movement, and loss of loved ones. So far there is no data that specifically indicates a direct causal relationship between work-from-home arrangements and increases or decreases in domestic violence. While lockdown requirements can equate to more time at home with an abusive partner, there might be also protective factors, such as increased observation by neighbours who are likewise at home. In line with this idea, a working paper by Miller and colleagues (2020), which investigated the effects of the pandemic on domestic violence in Los Angeles, reported ambiguous effects, which also highlight the difficulty and complexity of reliably measuring domestic violence. For instance, they reported an increase in domestic violence calls to the police, but the actual number of reported crimes and arrests went down. It remains unclear whether these results mean that the threshold for reporting domestic violence was reduced by the pandemic, which in turn might have prevented more severe crimes to occur, or whether police was just more reluctant to arrest individuals, due to fears of infection. Related to this topic is also the question of whether work-from-home arrangements have any effects on the occurrence of work-related harassment. Recent news reports have suggested that work-at-home arrangements might not have a beneficial effect regarding workplace harassment, and have even suggested a further increase, due to the lack of managerial oversight and the impersonal nature of telecommunication (Martinuzzi, 2020). It is, however, also possible that remote work offers several protective factors from workplace harassment such as the removal of physical intimidation and the opportunity to record any telecommunication. Reports on this topic are so far only anecdotal in nature, and a more comprehensive assessment of this topic will be required. In any case this issue highlights that managers should be aware of the social and domestic risks that mandatory work-from-home arrangements could entail and ensure that appropriate reporting and support mechanisms are in place and widely communicated to employees.

\section{Remote Work and Interindividual Differences}

The research reviewed here has highlighted that the suitability of work-at-home arrangements will vary based on both individual differences, and organizational requirements, both of which need to be considered to maximise positive outcomes and avoid negative outcomes for both individuals and organizations. Due to individual differences, a one-size-fits-all approach is not the best way to approach this issue. For example, Van Yperen and colleagues (2014) conducted a psychometric study on a sample from a wide range of occupations and organizations, finding that employees with a low need for autonomy and a strong need of relatedness are typically most negatively impacted by an absence of social contacts. In contrast, individuals that suffer from social anxiety feel more comfortable in remote, digitally mediated interactions (Prizant-Passal et al., 2016). Further, Clark et al. (2012) investigated the relationship between the classic Big Five personality dimensions (i.e. extraversion, agreeableness, conscientiousness, neuroticism, and openness; Digman, 1990) in relation to attitude towards telecommuting. Their study was based on quantitative self-reports and involved a sample of over 300 senior business students. The study highlighted a positive relationship between agreeableness and sympathetic attitudes towards telecommuting. Individuals with high levels of agreeableness are more likely to be empathetic, cooperative, and trusting (Digman, 1990), whereas disagreeable individuals may be more likely to display traits of self-centredness, competitiveness, and distrust. It is open for interpretation why this pattern emerged, but one interpretation is that employees who score lower on trust and empathy may find it more difficult to engage with virtual team structures. Another interesting finding by Clark and colleagues (2012) was that individuals high in neuroticism (i.e. more anxious and emotionally instable; Digman, 1990) prefer work-from-home arrangements. A possible interpretation of this finding is that remote working allows 
those individuals to avoid social situations that could trigger negative mood states and further allows them to avoid social stigma. Clark and colleagues did not observe significant relationships between the other three personality factors (i.e. extraversion, conscientiousness, and openness) and attitudes toward telework. In contrast, Smith et al. (2018), obtaining quantitative self-reports of a sample of over 300 U.S. teleworkers, found that the personality factor of openness predicted how comfortable workers were with using video and phone communications channels. This is particularly important since the same study reported that satisfaction with these remote communication styles was significantly associated with overall job satisfaction in teleworkers. Given that openness indicates the level to which individuals are adaptable to new situations and their preference for new experiences (Digman, 1990), it is not surprising that this factor is also related to the willingness and appreciation of engaging with technology. In line with the observation by Clark and colleagues (2012), Smith and colleagues also observed a correlation between agreeableness and employees' satisfaction with communication technologies used in remote working environments, which again emphasises the importance of this personality factor to predict potential challenges for some employees in undertaking remote work. Another relevant study on the topic of personality and telework employed a quantitative self-report method in over 700 U.S. public service employees (Anderson et al. 2015). The authors observed a more positive attitude towards telework in introverted versus extraverted individuals, which seems not surprising given that extraversion is associated with being highly sociable and assertive, for which remote work environments offer limited opportunities. Taken together, these studies suggest that it is critical therefore that organizations understand the interindividual differences in needs and personalities of their workforce in implementing work-from-home arrangements. It is likely to be the case that some individuals will do well under permanent work-from-home arrangements, while others may require a hybrid arrangement working both from home and from the office or other remote work locations during a typical work week.

\section{SOLUTIONS AND RECOMMENDATIONS}

Research suggests that remote work arrangements, across a range of industries, are generally related to increases in productivity (see Rupietta \& Beckmann (2016) for a large panel dataset), indicating that there is no need for management to feel too concerned about the performance and reliability of employees. However, the effectiveness of remote work for employees and organizations will depend on both the nature of work, and individual differences amongst employees (see also Allen, et al., 2015 for a review). Considering the potential cost-savings offered by work-at-home arrangements this paints an overall positive picture. From the perspective of the employee, the most significant benefits of work-from-home environments derive from the satisfaction of autonomy needs flowing from increased flexibility, however, this may only apply to work-from-home arrangements that are voluntary (Deci et al., 2017). However, while employees may not have been happy to have been forced out of the office, on a daily basis, each employee can get up and decide how to approach tasks with greater freedom than in the office.

The most significant concern related to work-from-home arrangements for both employers and employees appears to be the risk of social isolation that may eventually lead to organizational disenfranchisement (Achor et al., 2018). In particular, employees with high needs for social relatedness and who lack social-support networks at home are at risk, whereas those with low needs for relatedness and robust social networks outside of the office are likely to benefit (Van Yperen et al., 2014; Holt-Lunstad et al., 2015). Research has also shown that it will be important to develop approaches to regularly ap- 
praise performance in work-from-home arrangements, to avoid a scenario where reduced visibility of achievements leads to decrements in intrinsic motivation, especially for employees high in competence needs (Matsui et al., 1982; Bloom et al., 2015).

Moreover, whereas work-from-home arrangements can benefit intrinsic motivation for employees through the fulfilment of basic psychological needs of competence, relatedness, and autonomy (Ryan \& Deci, 2017), there are also more pragmatic determinants of performance and well-being in work from home environments. It is therefore important to consider the physical differences of work-from-home compared to office environments. The elimination of common distractors present in office environments, particularly the detrimental effects of noise and distraction in open plan offices (Sander et al., 2019), are likely to provide significant benefits for those working from home (see also chapter by Sander, Rafferty \& Jordan in this book). In addition to social dimensions of work environments, the effects of some dimensions of the physical work environment have also been shown to be moderated by personality factors, making it important to note that there is no one-size-fits-all solution for employees and employers. For example, research has shown that the detrimental effects of noise on cognitive performance is exacerbated in introverted individuals (Morgenstern et al., 1974, Standing et al., 1990, Belojevic et al., 2001), where more extroverted employees may in fact seek out noisier working environments (Campbell \& Hawley, 1982). In addition to taking into account physical differences between office and home environments, organizations must also pay attention to and adjust procedural and task related aspects of work. For instance, Microsoft has indicated that traditional meeting structures and schedules do not translate well into remote work environments (Miller, 2020). To address this, Microsoft reduced the duration of meetings from 1 hour to 30 minutes, and decreased the maximum number of participants in order to increase employee engagement and productivity.

Finally, it is important to emphasize that for a significant percentage of employees, work-from-home arrangements are preferred, however organizational limitations may present a barrier to this occurring. For instance, Mokhtarian \& Salomon (1996) discovered that more than half of their surveyed employees indicated that they would prefer to work from home if they could, but that the most frequent impediment for this was manager disapproval. It is important for organizations to be aware of potential barriers to the take up of work from home arrangements, and to address these through policy intervention, education and awareness programs.

\section{FUTURE RESEARCH DIRECTIONS}

Future research could explore several different avenues, in particular examining the effects of individual differences on work-from-home outcomes, differences in both job type and tasks that are suitable for work-from-home arrangements, and lastly, the effects of broader changes on social interaction and wellbeing under the pandemic on psychological outcomes of work-from-home. Firstly, as noted earlier in the chapter, research has started to highlight the profound effect of individual differences (demographic factors as well as personality types) on whether work-from-home arrangements are beneficial or detrimental to performance and well-being. By better understanding the role of individual differences on well-being and performance outcomes in work-from-home arrangements, organizations will be better placed to make appropriate decisions for their workforce. Secondly, more research is needed to assess differences in job types and work tasks, to determine how well they lend themselves to be accomplished from home. For example, tasks that require long periods of uninterrupted concentration may be better 
suited to work-from-home than tasks that require exchanging ideas and building consensus with other co-workers. Secondly, home-offices avoid many of the well-researched environmental nuisances of open-office environments. On the flip side, however, home-offices may feature several potential threats to cognitive performance and psychological well-being that will require more systematic investigation. Depending on demographic and economic context factors, home-offices may lack privacy, and as mentioned above, bear the potential for work-role conflict with other residents of the home (Duxbury \& Higgins, 2001; Lapierre et al., 2016). The COVID-19 pandemic presents an opportunity to evaluate cognitive-emotional distractors in home-offices across an unprecedentedly broad range of industries, roles and tasks. Finally, work-from-home arrangements under social-distancing requirements are likely to lead to even higher levels of loneliness than is typically the case, given that in many cities, private social contacts are being limited. This presents a new opportunity for researchers to understand how the limitations of the pandemic affect cognitive, emotional and relational outcomes for employees working from home. Without proper controls and rigorous empirical design, data acquired during social-distancing or lock down restrictions is likely to overestimate levels of loneliness associated with work-from-home environments. The physical and social well-being effects of working from home under pandemic restrictions have significant implications for both organizations and policy makers. As such, research to better understand these effects is important.

\section{CONCLUSION}

Though the long-term implications of COVID-19 are currently unknown, our review of the literature suggests that if individual differences and preferences are considered, work-from-home arrangements can both maintain, and potentially significantly increase productivity. While the pandemic and the restrictions on movement and work location present challenges, there is an opportunity for exploration and innovation in work-from-home arrangements. In this chapter we have made the case for structuring research findings and future efforts on work-from-home arrangements using the self-determination model of motivation (Ryan \& Deci, 2017). Focussing on the process of basic psychological need fulfilment in work-from-home settings can provide a valuable explanatory framework for the systematic investigation of characteristics that influence productivity, well-being, and personal growth. Taken together, while the reviewed evidence highlights that work-from-home arrangements can have a profound positive impact on satisfying psychological needs, organizations should be aware that if work-from-home arrangements are not voluntary, the decreased sense of autonomy may reduce intrinsic motivation, and ultimately lead to reduced levels of performance and well-being.

\section{REFERENCES}

Achor, S., Kellerman, G. R., Reece, A., \& Robichaux, A. (2018). America's loneliest workers, according to research. Harvard Business Review. https://hbr.org/2018/03/americas-loneliest-workers-accordingto-research

Advancing Parental Leave Equality Network. (2019). National working families report 2019. https:// aplen.pages.ontraport.net/WorkingFamiliesReport2019 
Allen, T. D., Golden, T. D., \& Shockley, K. M. (2015). How effective is telecommuting? Assessing the status of our scientific findings. Psychological Science in the Public Interest: A Journal of the American Psychological Society, 16, 40-68.

Altig, D., Baker, S. R., Barrero, J. M., Bloom, N., Bunn, P., Chen, S., Mizen, P., Parker, N., Renault, T., Smietanka, P., \& Thwaites, G. (2020). Economic uncertainty before and during the COVID-19 pandemic. Journal of Public Economics, 191, 104274. doi:10.1016/j.jpubeco.2020.104274 PMID:32921841

Anderson, A., Huttenlocher, D., Kleinberg, J., \& Leskovec, J. (2013). Steering user behavior with badges. Proceedings of the 22nd international conference on World Wide Web, 95-106. 10.1145/2488388.2488398

Anderson, A. J., Kaplan, S. A., \& Vega, R. P. (2015). The impact of telework on emotional experience: When, and for whom, does telework improve daily affective well-being? European Journal of Work and Organizational Psychology, 24(6), 882-897. doi:10.1080/1359432X.2014.966086

Anderson, D. I., Magill, R. A., \& Sekiya, H. (2001). Motor learning as a function of KR schedule and characteristics of task-intrinsic feedback. Journal of Motor Behavior, 33(1), 59-66. doi:10.1080/00222890109601903 PMID:11265058

Australian Bureau of Statistics. (2017). Childhood Education and Care, Australia. Cat no. 4402.0.

Banerjee, I., Jacobsen, R., Krivkovich, A., Libotte, G., \& Rambachan, I. (2020). Shaping and safeguarding the banking workforce after COVID-19. McKinsey \& Company. https://www.mckinsey.com/industries/ financial-services/our-insights/shaping-and-safeguarding-the-banking-workforce-after-covid-19\#

Baumeister, R., \& Leary, M. R. (1995). The need to belong: Desire for interpersonal attachments as a fundamental human motivation. Psychological Bulletin, 117(3), 497-529.

Belojevic, G., Slepcevic, V., \& Jakovljevic, B. (2001). Mental performance in noise: The role of introversion. Journal of Environmental Psychology, 21(2), 209-213. doi:10.1006/jevp.2000.0188

BickA.BlandinA.MertensK. (2020). Work from Home after the Covid-19 Outbreak. CEPR Discussion Paper No. DP15000. https://ssrn.com/abstract=3650114

Bliese, P. D., Edwards, J. R., \& Sonnentag, S. (2017). Stress and well-being at work: A century of empirical trends reflecting theoretical and societal influences. The Journal of Applied Psychology, 102(3), 389-402. doi:10.1037/ap10000109 PMID:28125263

Bloom, N., Liang, J., Roberts, J., \& Ying, Z. J. (2015). Does working from home work? evidence from a Chinese experiment. The Quarterly Journal of Economics, 130(1), 165-218. doi:10.1093/qje/qju032

Butler, R., \& Nisan, M. (1986). Effects of no feedback, task-related comments, and grades on intrinsic motivation and performance. Journal of Educational Psychology, 78(3), 210-216. doi:10.1037/00220663.78.3.210

Campbell, J. B., \& Hawley, C. W. (1982). Study habits and Eysenck's theory of extraversion-introversion. Journal of Research in Personality, 16(2), 139-146. doi:10.1016/0092-6566(82)90070-8 
Cantillon, B., Chzhen, Y., Sudhanshu, H., \& Nolan, B. (2017). Children of Austerity: Impact of the Great Recession on Child Poverty in Rich Countries. Oxford University Press. doi:10.1093/ oso/9780198797968.001.0001

Carnevale, J. B., \& Hatak, I. (2020). Employee adjustment and well-being in the era of COVID-19: Implications for human resource management. Journal of Business Research, 116, 183-187. doi:10.1016/j. jbusres.2020.05.037 PMID:32501303

Clark, A. L., Karau, S. J., \& Michalisin, M. D. (2012). Telecommuting Attitudes and the 'Big Five' Personality Dimensions. Journal of Management Policy and Practice, 13(3), 31-46.

Cooper, C. L., \& Marshall, J. (1976). Occupational sources of stress: A review of the literature relating to coronary heart disease and mental ill health. Journal of Occupational Psychology, 49(1), 11-28. doi:10.1111/j.2044-8325.1976.tb00325.x

Covington, M. V., \& Mueller, K. J. (2001). Intrinsic versus extrinsic motivation: An approach/avoidance reformulation. Educational Psychology Review, 13(2), 157-182. doi:10.1023/A:1009009219144

Csiksentmihalyi, M., Rathunde, K., \& Whalen, S. (1993). Talented teenagers: The roots of success and failure. Cambridge University Press.

Das, M., Das, A., \& Mandal, A. (2020). Examining the impact of lockdown (due to COVID-19) on Domestic Violence (DV): An evidences from India. Asian Journal of Psychiatry, 54, 102335. doi:10.1016/j. ajp.2020.102335 PMID:32801078

de Macêdo, T., Cabral, E., Silva Castro, W. R., de Souza, C. C. Junior, da Costa, J. F. Junior, Pedrosa, F. M., da Silva, A. B., de Medeiros, V., de Souza, R. P., Cabral, M., \& Másculo, F. S. (2020). Ergonomics and telework: A systematic review. Work (Reading, Mass.), 66(4), 777-778. doi:10.3233/WOR-203224 PMID:32925139

Deci, E. L. (1971). Effects of externally mediated rewards on intrinsic motivation. Journal of Personality and Social Psychology, 18(1), 105-115. doi:10.1037/h0030644

Deci, E. L., Olafsen, A. H., \& Ryan, R. M. (2017). Self-determination theory in work organizations: State of the science. Annual Review of Organizational Psychology and Organizational Behavior, 4(1), 19-43. doi:10.1146/annurev-orgpsych-032516-113108

Digman, J. M. (1990). Personality structure: Emergence of the five-factor model. Annual Review of Psychology, 41(1), 417-440. doi:10.1146/annurev.ps.41.020190.002221

Dockery, A. M., \& Bawa, S. (2014). Is working from home good work or bad work? Evidence from Australian employees. Australian Journal of Labour Economics, 17(2), 163-190.

Duxbury, C. \& Higgins, C. (2001). The 2001 national work-life conflict study. The Healthy Communities Division, Health Canada Report.

Ford, M. T., Cerasoli, C. P., Higgins, J. A., \& Decesare, A. L. (2011). Relationships between psychological, physical, and behavioural health and work performance: A review and meta-analysis. Work and Stress, 25(3), 185-204. doi:10.1080/02678373.2011.609035 
Grant, S., \& Betts, B. (2013). Encouraging user behaviour with achievements: An empirical study. Proceedings of the 10th Working Conference on Mining Software Repositories, 65-68 10.1109/MSR.2013.6624007

Hamari, J. Koivisto, J., \& Sarsa, H. (2014). Does gamification work? A literature review of empirical studies on gamification. System Sciences (HICSS), 3025-3034.

Hawisher, G. E., \& Moran, C. (1993). Electronic mail and the writing instructor. College English, 55(6), 627-643. doi:10.2307/378699

Holt-Lunstad, J., Smith, T. B., Baker, M., Harris, T., \& Stephenson, D. (2015). Loneliness and social isolation as risk factors for mortality: A meta-analytic review. Perspectives on Psychological Science, 10(2), 227-237. doi:10.1177/1745691614568352 PMID:25910392

Jarvenpaa, S. L., \& Leidner, D. E. (1999). Communication and trust in global virtual teams. Organization Science, 10(6), 791-815. doi:10.1287/orsc.10.6.791

Jetelina, K. K., Knell, G., \& Molsberry, R. J. (2020). Changes in intimate partner violence during the early stages of the COVID-19 pandemic in the USA. Injury Prevention: Journal of the International Society for Child and Adolescent Injury Prevention. Advance online publication.

Kello, J. E. (2015). The science and practice of workplace meetings. In J. A. Allen, N. Lehmann-Willenbrock, \& S. G. Rogelberg (Eds.), Cambridge handbooks in psychology. The Cambridge handbook of meeting science (pp. 709-734). Cambridge University Press. doi:10.1017/CBO9781107589735.030

Kuvaas, B., Buch, R., Weibel, A., Dysvik, A., \& Nerstad, C. G. (2017). Do intrinsic and extrinsic motivation relate differently to employee outcomes? Journal of Economic Psychology, 61, 244-258. doi:10.1016/j.joep.2017.05.004

Lapierre, L. M., Van Steenbergen, E. F., Peeters, M. C., \& Kluwer, E. S. (2016). Juggling work and family responsibilities when involuntarily working more from home: A multiwave study of financial sales professionals. Journal of Organizational Behavior, 37(6), 804-822. doi:10.1002/job.2075

Manochehri, G., \& Pinkerton, T. (2003). Managing telecommuters: Opportunities and challenges. American Business Review, 21(1), 9-16.

Martínez Sánchez, A., Pérez Pérez, M., de Luis Carnicer, P., \& José Vela Jiménez, M. (2007). Teleworking and workplace flexibility: A study of impact on firm performance. Personnel Review, 36(1), 42-64. doi:10.1108/00483480710716713

Martinuzzi, E. (2020, June 17). As Work Has Moved Home, So Has Harassment. Bloomberg. https:// www.bloomberg.com/opinion/articles/2020-06-17/as-work-has-moved-home-so-has-online-bullyingharassment

Mathieu, J. E., Heffner, T. S., Goodwin, G. F., Salas, E., \& Cannon-Bowers, J. A. (2000). The influence of shared mental models on team process and performance. The Journal of Applied Psychology, 85(2), 273-283. doi:10.1037/0021-9010.85.2.273 PMID:10783543

Matsui, T., Okada, A., \& Kakuyama, T. (1982). Influence of achievement need on goal setting, performance, and feedback effectiveness. The Journal of Applied Psychology, 67(5), 645-648. doi:10.1037/00219010.67.5.645 
Mehrabian, A. (1972). Nonverbal communication. Aldine- Atherton.

Mencl, J., Wefald, A. J., \& van Ittersum, K. W. (2016). Transformational leader attributes: Interpersonal skills, engagement, and well-being. Leadership and Organization Development Journal, 37(5), 635-657. doi:10.1108/LODJ-09-2014-0178

Miller, A. R., Segal, C., \& Spencer, M. K. (2020). Effects of the COVID-19 Pandemic on Domestic Violence in Los Angeles. National Bureau of Economic Research, 28068.

Miller, C. C. (2020, July 31). Remote Work Isn't Working? Maybe Your Company Is Doing It Wrong. The New York Times. https://www.nytimes.com/2020/07/31/upshot/remote-work-tips.html

Mokhtarian, P. L., \& Salomon, I. (1996). Modeling the choice of telecommuting: 2. A case of the preferred impossible alternative. Environment \& Planning, 28(10), 1859-1876. doi:10.1068/a281859

Morgenstern, S., Hodgson, R. J., \& Law, L. (1974). Work efficiency and personality. Ergonomics, 17(2), 211-220. doi:10.1080/00140137408931340 PMID:4845889

Nakamura, J., \& Csikszentmihalyi, M. (2002). The concept of flow. In C. R. Snyder \& S. J. Lopez (Eds.), Handbook of positive psychology (pp. 89-105). Oxford University Press.

Oprean, D., Simpson, M., \& Klippel, A. (2017). Collaborating Remotely: An evaluation of immersive capabilities on spatial experiences and team membership. International Journal of Digital Earth, 11(4), $1-17$.

Ozcelik, H., \& Barsade, S. (2011). Work loneliness and employee performance. Academy of Management Annual Meeting Proceedings, 1-6.

Peterman, A., Potts, A., O'Donnell, M., Thompson, K., Shah, N., Oertelt-Prigione, S., \& van Gelder, N. (2020). Pandemics and violence against women and children. Center for Global Development Working Paper 528. Washington, DC: Centre for Global Development.

Pew Research Center (2015). Raising Kids and Running a Household: How Working Parents Share the Load. Technical Report.

Pittman, T. S., Boggiano, A. K., \& Ruble, D. N. (1983). Intrinsic and extrinsic motivational orientations: Limiting conditions on the undermining ad enhancing effects of reward on intrinsic motivation. In J. Levine \& M. Wang (Eds.), Teacher and student perceptions: Implications for learning (pp. 319-340). Erlbaum.

Prizant-Passal, S., Shechner, T., \& Aderka, I. M. (2016). Social anxiety and Internet use-A meta-analysis: What do we know? What are we missing? Computers in Human Behavior, 62, 221-229. doi:10.1016/j. chb.2016.04.003

Ransome, P. (2007). Conceptualizing boundaries between 'life' and 'work'. International Journal of Human Resource Management, 18(3), 374-386. doi:10.1080/09585190601167425

Reis, H. T. (2014). Responsiveness: Affective interdependence in close relationships. In M. Mikulincer \& P. R. Shaver (Eds.), The Herzliya series on personality and social psychology. Mechanisms of social connection: From brain to group (pp. 255-271). American Psychological Association. 
Reiss, S. (2012). Intrinsic and extrinsic motivation. Teaching of Psychology, 39(2), 152-156. doi:10.1177/0098628312437704

Rice, R. E., \& Love, G. (1987). Electronic emotion: Socioemotional content in a computer-mediated communication network. Communication Research, 14(1), 85-108. doi:10.1177/009365087014001005

Rupietta, K., \& Beckmann, M. (2016). Working from home: What is the effect on employees' effort? University of Basel, Centre of Business and Economics.

Russell, D. W. (1996). The UCLA Loneliness Scale (Version 3): Reliability, validity, and factor structure. Journal of Personality Assessment, 66(1), 20-40. doi:10.120715327752jpa6601_2 PMID:8576833

Ryan, R. M. (1993). Agency and organization: Intrinsic motivation, autonomy, and the self in psychological development. In J.E. Jacobs (Ed.), Nebraska Symposium on Motivation: Developmental perspectives on motivation (pp. 397-427). Academic Press.

Ryan, R. M., \& Deci, E. L. (2000). Self-determination theory and the facilitation of intrinsic motivation, social development, and well-being. The American Psychologist, 55(1), 68-78. doi:10.1037/0003066X.55.1.68 PMID:11392867

Ryan, R. M., \& Deci, E. L. (2017). Self determination theory. The Guildford Press.

Ryan, R. M., \& Powelson, C. L. (1991). Autonomy and relatedness as fundamental to motivation and education. Journal of Experimental Education, 60(1), 49-66. doi:10.1080/00220973.1991.10806579

Sailer, M., Hense, J. U., Mayr, S. K., \& Mandl, H. (2017). How gamification motivates: An experimental study of the effects of specific game design elements on psychological need satisfaction. Computers in Human Behavior, 69, 371-380. doi:10.1016/j.chb.2016.12.033

Sander, E. L. J., Caza, A., \& Jordan, P. J. (2019). Psychological perceptions matter: Developing the reactions to the physical work environment scale. Building and Environment, 148, 338-347. doi:10.1016/j. buildenv.2018.11.020

Sander, L., \& Bauman, O. (2020). Why Zoom Meetings are So Exhausting. In M. Glassey (Ed.). 2020: The year that changed us. Thames \& Hudson.

Scandura, T., \& Lankau, M. (1997). Relationships of Gender, Family Responsibility and Flexible Work Hours to Organizational Commitment and Job Satisfaction. Journal of Organizational Behavior, 18(4), 377-391. doi:10.1002/(SICI)1099-1379(199707)18:4<377::AID-JOB807>3.0.CO;2-1

Smith, S. A., Patmos, A., \& Pitts, M. J. (2018). Communication and teleworking: A study of communication channel satisfaction, personality, and job satisfaction for teleworking employees. International Journal of Business Communication, 55(1), 44-68. doi:10.1177/2329488415589101

Song, Y. (2009). Unpaid Work at Home. Industrial Relations, 48(4), 578-588. doi:10.1111/j.1468232X.2009.00576.X

Song, Y., \& Gao, J. (2018). Does telework stress employees out? A study on working at home and subjective well-being for wage/salary workers. Institute of Labor Economics (IZA). 
Standing, L., Lynn, D., \& Moxness, K. (1990). Effects of noise upon introverts and extroverts. Bulletin of the Psychonomic Society, 28(2), 138-140. doi:10.3758/BF03333987

Stansfeld, S., \& Candy, B. (2006). Psychosocial work environment and mental health-a meta-analytic review. Scandinavian Journal of Work, Environment \& Health, 32(6), 443-462. doi:10.5271jweh.1050 PMID: 17173201

Steers, R. M., \& Spencer, D. G. (1977). The role of achievement motivation in job design. The Journal of Applied Psychology, 62(4), 472-479. doi:10.1037/0021-9010.62.4.472

Taris, T. W., \& Schreurs, P. J. G. (2009). Well-being and organizational performance: An organizational-level test of the happy-productive worker hypothesis. Work and Stress, 23(2), 120-136. doi:10.1080/02678370903072555

Thayer, J. F., Verkuil, B., Brosschot, J. F., Kampschroer, K., West, A., Sterling, C., ... Sternberg, E. M. (2010). Effects of the physical work environment on physiological measures of stress. European Journal of Cardiovascular Prevention and Rehabilitation, 17(4), 431-439. doi:10.1097/HJR.0b013e328336923a PMID:20404733

Troup, C., \& Rose, J. (2012). Working from home: Do formal or informal telework arrangements provide better work-family outcomes? Community Work \& Family, 15(4), 471-486. doi:10.1080/13668803.20 12.724220

Van Yperen, N. W., Rietzschel, E. F., \& De Jonge, K. M. (2014). Blended working: For whom it may (not) work. PLoS One, 9(7), e102921. doi:10.1371/journal.pone.0102921 PMID:25033202

Vergallito, A., Mattavelli, G., Gerfo, E. L., Anzani, S., Rovagnati, V., Speciale, M., Vinai, P., Vinai, P., Vinai, L., \& Lauro, L. (2020). Explicit and Implicit Responses of Seeing Own vs. Others' Emotions: An Electromyographic Study on the Neurophysiological and Cognitive Basis of the Self-Mirroring Technique. Frontiers in Psychology, 11, 433. doi:10.3389/fpsyg.2020.00433 PMID:32296363

White, R. W. (1959). Motivation reconsidered: The concept of competence. Psychological Review, 66(5), 297-333. doi:10.1037/h0040934 PMID:13844397

Wilder, D. A., \& Thompson, J. E. (1980). Intergroup contact with independent manipulations of in-group and out-group interaction. Journal of Personality and Social Psychology, 38(4), 589-603. doi:10.1037/0022-3514.38.4.589

\section{ENDNOTE}

1 Deci \& Ryan (2000) proposed four different types of extrinsic motivation, ranging from fully externally regulated to a state that is supposedly indistinguishable from intrinsic motivation. The full model has, however received so far only limited empirical support. 